\title{
Global Ageing in the Twenty-First Century: Challenges, Opportunities and Implications
}

\author{
edited by Susan McDaniel and Zachary Zimmer \\ United States: Ashgate 2013 \\ ISBN: 978-1-4094-3271-5 \\ Hardcover, \$119.95, 344 pp.
}

\author{
Reviewed by Andrew Wister \\ Department of Gerontology, Simon Fraser University
}

It was reported by the United Nations (2002) at the Second World Assembly on Ageing that, for the first time in history, the number of older people in the world will outnumber younger people by 2050. While nations and communities continue to adapt policy and practice to changes in the age structure, we are only beginning to think about ageing at a global community-level. In their edited volume entitled, Global Ageing in the TwentyFirst Century: Challenges, Opportunities and Implications, McDaniel and Zimmer have brought together researchers from a diverse set of developing and developed countries/regions in order to identify major issues linked to the intersection of population ageing with health, social, economic and political dimensions. Up until recently, most focus has been on the relationship between population ageing and economic growth in developed countries. However, our understanding of the incredibly unique and diverse experiences of countries around the world, and the translation of knowledge across borders, has moved into a new and expanding phase of investigation. McDaniel and Zimmer's collection is a welcome addition to this burgeoning field, forging new territory for the development of global perspectives on ageing. While some chapters are situated within a particular nation or region in the world, and others provide cross-national comparative work, together they address both generic and unique circumstances and implore the reader to envision these within a broader policy lens. The editors have not been deterred by the complexities of global ageing, but rather, have woven together a set of papers that afford a solid foothold to scale the age pyramids of the world. Their book contains 17 chapters divided into three parts: I) Healthy Ageing and Health Care; II) Ageing Workforce, Retirement and the Provision of Pensions; and III) Shifting Intergenerational Relations.

A challenge to reviewing a large edited volume is to provide adequate coverage of individual chapters, while connecting them in a coherent manner so that readers appreciate that the whole is greater than the parts. I commend McDaniel and Zimmer for providing both an Introduction chapter (1) to set the stage, as well as a Conclusion (17) in which each chapter is summarized, leading to future directions at the theoretical, research and policy levels. Rather than attempting to adequately summarize 17 chapters, I will focus on substantive issues raised in the volume with material chosen from selected chapters.

The opening introductory chapter by Zimmer and McDaniel frames the book by detailing variations in population ageing experiences both within and between developing and developed nations. While more developed countries are 'older', it is the developing countries that are experiencing a considerably faster rate of ageing (known as compression of aging). The dynamic nature of population ageing, such as the speed at which it occurs and the surrounding contexts, creates economic and social challenges for individual counties and regions, as well as at a global level. How do health systems adapt? What are the most pressing workforce, retirement and pension system issues? And how will intergenerational relationships transform and be transformed by population ageing experiences around the world? A rationale is also provided for the three sections of the 
book that attempt to provide partial answers to these pressing questions. The second chapter (by Francois Héran) complements the first, introducing key concepts and processes of global ageing. Population ageing is multifaceted, driven by expanded life expectancy at the top of the age structure; shrinking fertility at the bottom; the aging of the baby boom generation in the middle (for countries with a boom); and migration patterns, especially emigration of younger workers. The author challenges the reader to think about the integral nature of ethical and political choices that we make, and whether there is a 'demographic good' associated with such decisions.

Chapters 3 through 8 address issues of healthy ageing and health care within and across a wide array of countries. For instance, Moneer Alam shows that functional disabilities have striking gender effects among older adults in Delhi. Ajrouch et al. present rare data for Algeria, Lebanon, and Palestinian on self-rated health and disability of older adults, demonstrating similar epidemiological transitions for these countries, as well as linkages with gender, SES, literacy and family/social relations. In a comparative analysis of eight countries, Crimmins et al. provide evidence that there is considerable heterogeneity in age-related physiological biomarkers across countries and indicators connected to different ageing experiences, health care systems, and age-period-cohort interactions. Turning to the sub-Sahara, Isabella Aboderin presents a number of policy challenges for a region that has been under the weight of acute disease pandemics and thus unable to adequately address the unique challenges of population ageing. Drawing on data from the Netherlands, Dorly Deeg revisits several myths of ageing and population health, including the role of healthy lifestyles in longevity; the paradox of declining disability, but increasing prevalence of many chronic illnesses; and whether future older adults will be healthier? While answers to these questions are still incomplete, there appears to be increasing diversity, requiring more flexible health care and institutional structures.

Part II is comprised of three chapters covering the ageing workforce, retirement and pensions. Codrina Rada revisits the long standing problems with dependency ratios as indicators of economic growth and sustainability. 'Effective' worker rates that capture innovation and productivity need to replace crude dependency ratios. If we accept the assumption that economic productivity requires growth in the labour market, then we also need closer examination of changing female labour markets at the nation, region and global levels. Recognizing that Europe is experiencing a decline in work expectancies and a need for revision in pension systems, Kathrin Komp argues that the definitions and meanings of ageing are significantly influenced by the policy environment, resulting in a return to a traditional frailty-dependency' model. The question of how older adults will fare in an information technology-based economy is tackled by Jovic and McMullin with the unsettling conclusion that we know little about this emerging field littered with potentially risky outcomes for older workers and society.

The final section deals with shifting intergenerational relations comprised of chapters 12 through 16 . Sara Arber details implications of globalization on several interrelated intergenerational relations, including: international migration of young and middle-aged workers (e.g., from the Philippines to many countries as care aides), migration from rural to urban areas (e.g., China), changes due to increased female labour force participation on caregiving roles and responsibilities, declines in three-generation families in many countries, as well as declining birth rates and increases in childlessness. Issues pertaining to intergenerational transfers and feminization of later life are given prominence in this discussion. Neena Chappell complements the above chapter comparing 'East' and 'West' social cohesion, including filial piety and other normative structures, among caregivers. Supported by a cross-national study of filial caregivers, results demonstrate that the translation of social cohesion into certain types of social capital are culturally dependent. Janet Fast analyzes the Canadian General Social Survey (2007) and shows that eldercare tends to be intergenerational, while most care for non-seniors is provided by someone of the same generation. Further, important policy issues are raised based on findings, such as: caregiving of seniors, especially by a spouse, is not as costly as caregiving for persons of younger ages. Finally, differences in loneliness between Russia and Bulgaria and across a number of determinants such as health and SES are revealed by Kim Korinek. Intergenerational transfers are further examined across 21 diverse countries by Leeson and Khan, who show that differences in levels of 'welfarism' are crucial in affecting how older people, especially older women, fare in a global context. 
McDaniel and Zimmer leave us with a thought provoking final chapter. In addition to providing a summary of the chapters contained in this volume, the editors articulate a number of policy lessons that require urgent consideration. We are then beckoned to rise to a number of challenges and to engage our sociological and demographic imaginations to further expand our understanding of global ageing. As pioneers, they are limited by the paucity of available studies and knowledge, but without a doubt, this book sets important groundwork upon which further research can be built.

The field of global ageing needs the attention of the research and policy arenas to move into its next phase of development. Given the rapid speed of global ageing that we are witnessing, we can not wait. Global Ageing in the Twenty-First Century: Challenges, Opportunities and Implications is a must read for anyone interested in this exciting emerging specialization. McDaniel and Zimmer are to be commended for making important inroads in their edited volume. But just as important is the vacuum that they leave to be filled with further work that can elucidate the complex interrelationships among population ageing at a global level and key domains within which policy and practice must be retrofitted to adapt to the future needs of countries, regions and the global community.

\section{References:}

United Nations. 2002. World Population Ageing, 1950-2002. New York: United Nations, Department of Economic and Social Affairs, Population Division. 